\title{
Endotracheal Tube and Proseal Laryngeal Mask Airway in Elderly Hypertensive Diabetic Patients Undergoing Routine Laparoscopic Surgical Procedures: A Comparison of Hemodynamic Parameters
}

\author{
MM RAHMAN ${ }^{\mathrm{a}}$, MMH MUNIR $^{\mathrm{b}}, \mathrm{K}^{\mathrm{S}} \mathrm{SARDAR}^{\mathrm{c}}$, AS KHAN $^{\mathrm{d}}$, AKMN CHOWDHURY $^{\mathrm{e}}$, \\ MK RAHMAN ${ }^{f}$, SK MONDAL ${ }^{g}$
}

\begin{abstract}
Summary:
Background: The effects of ProSeal laryngeal mask airway (PLMA) removal and tracheal extubationon cardiovascular responses were studied in elderly hypertensive diabetic patients in a randomize double-blind study.

Methods: A total of 60 elderly controlled diabetic hypertensive American Society of Anesthesiologists II \& III patients were randomly allocated to two groups (n-30 of each) for PLMA insertion or endotracheal intubation. $A$ standardized anesthetic sequence was used for induction and maintenance of anesthesia. The two groups were then compared for haemodynamic changes at the time of extubation/PLMA removal.
\end{abstract}

Results: In PLMA group, heart rate increased during PLMA removal but remained elevated for only 3 minutes

\section{Introduction:}

Diabetes mellitus is the most common endocrine abnormality encountered in surgical patients and is

a. Dr. Md. Mushfiqur Rahman, Associate Professor, Department of Anaesthesia, Analgesia \& Surgical-ICU, BIRDEM General Hospital, Shahbagh, Dhaka.

b. Dr. Md. Mhbubul Hasan Munir, Associate Professor, Department of Anaesthesia, Analgesia \& Surgical-ICU, BIRDEM General Hospital, Shahbagh, Dhaka.

c. Dr. Kawsar Sardar, Professor \& Head, Department of Anaesthesia, Analgesia \& Surgical-ICU, BIRDEM General Hospital, Shahbagh, Dhaka.

d. Prof. Abdus Salam Khan, Professor, Department of Anaesthesia, Analgesia \& Surgical-ICU, BIRDEM General Hospital, Shahbagh, Dhaka.

e. Prof.AKM Nurnobi Chowdhury, Professor \& Head, Department of Anaesthesia, Analgesia \& Surgical-ICU, BIRDEM General Hospital, Shahbagh, Dhaka.

f. Dr. Md. Khalilur Rahman, Senior Consultant (Hon), Department of Anaesthesia, Analgesia \& Surgical-ICU, BIRDEM General Hospital, Shahbagh, Dhaka.

g. Dr. Samiron Kumar Mondal, Associate Professor, Department of Surgery, BIRDEM General Hospital, Shahbagh, Dhaka.

Address of Correspondence: Dr. Md.Mushfiqur Rahman, Associate Professor, Dept. of Anaesthesia \& Surgical-ICU, Ibrahim Medical College \& BIRDEM. e-mail: rahmaanmushfique@gmail.com. Cell no. +8801673900939

Received: 12 November, 2017

Accepted: 27 May, 2018 while mean arterial pressure remained elevated for only 2 minutes. The elevations of heart rate and mean arterial pressure were exaggerated in the extubation group and persisted for more than 5 minutes. No complication was observed in any patient and no difficulty was encountered in insertion of PLMA in any patient.

Conclusion: Elderly hypertensive diabetic patients are at risk of exaggerated pressor response at the time of extubation. PLMA removal is associated with fewer hemodynamic changes than tracheal extubation and should be preferred wherever possible.

Key word: Proseal laryngeal mask airway, laparoscopic surgery, hypertensive type-2 diabetic patient,

(J Bangladesh Coll Phys Surg 2018; 36: 153-158)

DOI: http://dx.doi.org/10.3329/jbcps.v36i4.38184

associated with increased perioperative morbidity and mortality mainly due to the complications of the disease. ${ }^{1}$

Diabetic patients frequently have cardiovascular disorders such as hypertension, ischaemic heart disease and left ventricular dysfunction and very often associated with autonomic neuropathy which may aggravate during instrumentation of airway and anaesthesia. ${ }^{1}$ Therefore effective measures are to be sought to reduce these responses and minimize intraoperative hazards.

Till date, the cuffed tracheal tube was considered as the gold standard for providing a safe glottic seal, especially for laparoscopic procedures under general anaesthesia. ${ }^{2}$ The disadvantages of tracheal intubation, which involves rigid laryngoscopy, are in terms of concomitant haemodynamic responses and damage to the oropharyngeal structures at insertion. Postoperative sore throat is also a serious concern. This precludes the global utility of the tracheal tube and requires a better alternative. ${ }^{3}$

Tracheal extubation is usually performed with the patient in a lighter stage of anesthesia as compared to 
intubation and thus produces a significant increase in heart rate and blood pressure.

These autonomic responses may be dangerous especially in geriatric hypertensive diabetic patients and may lead to myocardial ischemia, ${ }^{4}$ infarction, arrhythmias, ${ }^{5}$ and raised intraocular pressure (IOP). ${ }^{6}$

The elderly diabetic patients have a diminished physiological reserve, alterations in autonomic function, an increased risk of coexisting cardiac disease, ${ }^{7}$ and increased sensitivity to opioids and anesthetic drugs. ${ }^{8}$

Therefore, an alteration of the anesthetic technique is preferable to pharmacological means to blunt the pressor response in this class of patients.

The classical laryngeal mask airway (CLMA) is preferred in such patients because insertion as well as removal of CLMA causes a transient rise of heart rate (HR), systolic blood pressure, and mean arterial pressure (MAP) similar to endotracheal intubation (ETT) in normotensive patients but of lesser severity and remains for a shorter period..$^{7-9}$ Unfortunately, CLMA cannot be used in many situations, where it has been largely replaced by the ProSeal laryngeal mask airway (PLMA).

PLMA was introduced as an improvement over CLMA by Brain in $2000 .{ }^{10}$ It has a dorsal cuff that presses the ventral cuff more firmly into the periglottic tissues leading to a better seal and permits high airway pressures without leak. The drain tube parallel to the ventilation tube permits drainage of passively regurgitated gastric fluid away from the airway and serves as a passage for gastric tube. ${ }^{10}$ The PLMA is a relatively new airway device in developing nations.

In spite of its popularity, no study so far has been done in elderly patients with diabetic and hypertension to compare the hemodynamic response using PLMA rather than a standard tracheal tube. With this background, the present study was undertaken to compare the circulatory responses to PLMA insertion/ removal and tracheal intubation/extubation and evaluate the intraoperative and postoperative laryngopharyngeal morbidity (LPM) occurring during general anaesthesia in elderly hypertensive diabetic patients undergoing laparoscopic surgeries.

\section{Methods:}

This prospective, randomized study was carried out after approval of the hospital ethics committee. A total of 60 hypertensive diabetic American Society of Anesthesiologists II-III patients aged 55- 75 years undergoing elective surgery were included in this study and were divided into the following groups: Group ETT, consisting of 30 hypertensive patients in whom ETT was performed; and Group PLMA, with 30 hypertensive patients in whom PLMA was used.

Only controlled hypertensive diabetic patients were included in this study. Patients with a history of angina, with electrocardiographic evidence of ischemic heart disease, with obesity, with chronic obstructive airway disease, with uncontrolled diabetes mellitus or with any other associated chronic medical problem were excluded from the study. All antihypertensive drugs were continued during the perioperative period, except angiotensin-converting-enzyme inhibitors, angiotensin receptor blockers, and diuretics. These drugs were withheld on the morning of surgery (in the case of angiotensin receptor blockers, 24 hours prior to surgery). All patients received tab. midazolam $7.5 \mathrm{mg}$ tablet at bedtime the night before surgery. On the morning of the surgery, the patients received $40 \mathrm{mg}$ omeprazole intravenously (IV), 60minutes before surgery.

All patients were monitored for heart rate, blood pressure (systolic and mean), electrocardiography, and oxygen saturation.

Patients received IV Ringer's lactate $5 \mathrm{~mL} / \mathrm{kg}$ over 5 10 minutes before the induction of anesthesia.

Blood pressure (systolic and mean) and heart rate was recorded just before induction as baseline values. An injection of fentanyl 2 microgm $/ \mathrm{kg}$ was given IV to the patient just before induction. Anesthesia was induced with IV propofol (1\% solution) $2 \mathrm{mg} / \mathrm{kg}$ followed by IV atracuronium bromide $0.5 \mathrm{mg} / \mathrm{kg}$ to facilitate endotracheal intubation or PLMA insertion in a randomized manner with a coin flip. An appropriate sized PLMA or ETT was used. Water soluble jelly was applied to both PLMA and ETT. An introducer was used to insert PLMA. Recommended volumes of air injected into a pilot balloon of PLMA/ETT to achieve a seal.

Once tracheal intubation/PLMA insertion was completed, anesthesia was maintained with helothane 0.5-0.8\% and $\mathrm{N}_{2} \mathrm{O}: \mathrm{O}_{2}(60: 40)$. Ventilation was controlled manually and was adjusted to maintain at 
35-45 mmHg. Top-ups of atracuronium bromide with $25 \%$ of the original loading dose were administered every 20 minutes. At the end of surgery, $\mathrm{N}_{2} \mathrm{O}$ and helothane were discontinued. Neuromuscular block was reversed by administration of a premixed combination of atropine and neostigmine. Before extubation or PLMA removal oropharyngeal secretions were sucked out. Patients were assessed for their ability to breathe spontaneously and open their eyes upon command. After extubation/PLMA removal, patients received $100 \%$ oxygen by facemask for 10 minutes.

Systolic arterial pressure (SBP), Diastolic arterial pressure (DBP) and mean arterial pressure (MAP) and heart rate were recorded at intervals of 5 minutes following induction until the end of surgery, at the time of extubation/PLMA removal, and then 1 minute, 2 minutes, 3 minutes, 5 minutes, and 10 minutes after removal of ETT/PLMA.

The data are expressed as mean \pm standard deviation. All analyses were performed using SPSS-17 software. The continuous data were statistically analyzed using two-sample independent t test and paired t test, and categorical data by Pearson's Chi-square/Fisher's exact test as appropriate. A p value $<0.05$ was considered to be statistically significant.

\section{Results:}

Sixty patients were entered into the study. There were no differences between the groups with respect to sex, weight, height, age, and antihypertensive use (Table 1).

Baseline values of hemodynamic variables were comparable between the two groups. The majority of patients were taking angiotensin-converting-enzyme inhibitors $(76 \%)$ followed by Calcium channel blockers (13\%) as an antihypertensive.

Increase of heart rate was observed in both the groups but the rise of heart rate in the ETT group was significant at 1 minute, 2 minutes, 3 minutes, and 5 minutes post extubation as compared to PLMA removal.

The difference was not significant at 10minutes after ETT/PLMA removal (Table 2).MAP also increased significantly in the ETT group as compared to the PLMA group and the rise was also significant at 1 minute, 2minutes, 3 minutes, 5 minutes, and 10 minutes after extubation as compared to PLMA removal (Table 3).

No patient in either group had any complication; PLMA insertion was successfully accomplished in all patients.

Table-I

\begin{tabular}{lcccc}
\multicolumn{5}{c}{ Patient characteristics } \\
Characteristics & ETT ( $\mathrm{n}=30)$ & PLMA $(\mathrm{n}=30)$ & P- value & \\
\hline Age (y) & $65 \pm 5$ & $66 \pm 6$ & 0.331 & $\mathrm{NS}$ \\
Sex ratio (F:M) & $19: 11$ & $18: 12$ & 0.555 & NS \\
Height (cm) & $154 \pm 6$ & $155 \pm 8$ & 0.127 & NS \\
Weight (kg) & $65 \pm 7$ & $66 \pm 8$ & 0.255 & NS \\
Type of surgery & \% of patients & \% of patients & & \\
Lap cholecystectomy & 82 & 84 & \\
Lap appendicectomy & 10 & 10 & \\
Lap. adrinalectomy & 08 & 06 & \\
Anti diabetic therapy & & & \\
Insulin & 67 & 65 & \\
Oral Hypoglycemic Agent & 33 & 35 & \\
Antihypertensive drugs & $\%$ of patients & $\%$ of patients & \\
b-blockers & 12 & 09 & \\
ACE inhibitors & 73 & 74 & \\
Calcium channel blockers & 10 & 13 & \\
Others & 05 & 04 & \\
\hline
\end{tabular}

All values are expressed as mean \pm standard deviation or $\%$ of patients; $p<0.05$ was considered significant. ACE $=$ angiotensin-converting enzyme; ETT = endotracheal tube group; PLMA = ProSeal laryngeal mask airway group. 


\section{Table-II}

Comparison of mean heart rate between endotracheal tube group (ETT) and ProSeallaryngeal mask airway group (PLMA).

\begin{tabular}{lccc} 
Heart rate (beats/min) & ETT $(\mathrm{n}=30)$ & PLMA $(\mathrm{n}=30)$ & $\mathrm{p}$-value \\
\hline Baseline & $89.56 \pm 10.56$ & $86.85 \pm 10.09$ & 0.314 \\
During extubation/PLMA removal & $102.03 \pm 9.32$ & $101.02 \pm 16.76$ & 0.774 \\
Postextubation/PLMA removal at $1 \mathrm{~min}$ & $133.96 \pm 10.74$ & $103.56 \pm 15.98$ & 0.023 \\
Postextubation/PLMAremoval at $2 \mathrm{~min}$ & $129.77 \pm 10.21$ & $99.79 \pm 14.32$ & 0.032 \\
Postextubation/PLMAremoval at $3 \mathrm{~min}$ & $125.98 \pm 10.01$ & $95.34 \pm 15.02$ & 0.012 \\
Postextubation/PLMAremoval at $5 \mathrm{~min}$ & $114.21 \pm 10.87$ & $93.25 \pm 12.24$ & 0.024 \\
Postextubation/PLMAremoval at $10 \mathrm{~min}$ & $92.67 \pm 7.89$ & $88.73 \pm 10.11$ & 0.094 \\
\hline
\end{tabular}

All values are expressed as mean \pm standard deviation; $\mathrm{p}<0.05$ indicates significance.

Table-III

Comparison of mean arterial pressure (MAP) between the endotracheal tube group(ETT) and ProSeal laryngeal mask airway group (PLMA).

\begin{tabular}{lccc} 
MAP (mmHg) & ETT $(\mathrm{n}=30)$ & PLMA $(\mathrm{n}=30)$ & p-value \\
\hline Baseline & $107.22 \pm 4.87$ & $105.31 \pm 4.09$ & 0.314 \\
During extubation/PLMA removal & $120.03 \pm 5.32$ & $108.02 \pm 5.76$ & 0.774 \\
Postextubation/PLMAremoval at $1 \mathrm{~min}$ & $127.96 \pm 4.74$ & $113.56 \pm 5.98$ & 0.021 \\
Postextubation/PLMAremoval at $2 \mathrm{~min}$ & $124.77 \pm 4.67$ & $109.79 \pm 7.32$ & 0.001 \\
Postextubation/PLMAremoval at $3 \mathrm{~min}$ & $119.98 \pm 5.01$ & $105.34 \pm 6.02$ & 0.001 \\
Postextubation/PLMAremoval at $5 \mathrm{~min}$ & $114.21 \pm 6.87$ & $105.25 \pm 4.24$ & 0.021 \\
Postextubation/PLMAremoval at $10 \mathrm{~min}$ & $108.67 \pm 4.89$ & $105.73 \pm 4.11$ & 0.094 \\
\hline
\end{tabular}

All values are expressed as mean \pm standard deviation; $\mathrm{p}<0.05$ indicates significance.

\section{Discussion:}

Our results showed that patients in whom PLMA was used had an attenuated pressor response at the time of its removal as compared to patients in whom ETT was used. The observed tachycardia at the time of extubation/PLMA removal in the two groups revealed a significant difference between these two groups at 1 minute, 2 minutes, and 3 minutes of this study (Table 2).

Similarly, the changes in MAP were of lesser magnitude and of shorter duration in the PLMA group as compared to the ETT group (Tables 3) and these findings were consistently observed in all patients with hypertension. Hypertensive patients exhibit an exaggerated hemodynamic response to awakening and tracheal extubation compared to that seen in patients without hypertension.

Classical laryngeal mask airway (CLMA), designed by Brain in 1983, was found to be helpful in such patients as cardiovascular responses to its insertion as well as removal are minimal, which may be related to lack of direct laryngeal and tracheal stimulation, and lesser stimulation of the pharynx. ${ }^{10}$ The effectiveness of LMA in preventing the increase in heart rate, MAP and SAB, and DAP and thus increased myocardial oxygen demand in both normotensive and hypertensive patients has been shown by Fuji et al. ${ }^{9,}$ 11,12

Although these hemodynamic changes during extubation or LMA removal are short lived, they can be of dangerous consequences in geriatric patients 
especially those patients who have coexisting coronary artery disease, if $\mathrm{HR}>130$ and $\mathrm{SBP}>160$, or rate pressure product ( systolic arterial pressure $\mathrm{X}$ heart rate.) $>20,000$ signifying increased myocardial oxygen demand. Therefore, the prevention of these hemodynamic changes during tracheal extubation is of particular clinical importance in patients with hypertension. ${ }^{13-16}$ Geriatric patients may be at a particular risk.

Cardiovascular complications of diabetes along with hypertension and ischemic heart disease are common in the elderly. In addition, decreased autoregulation and sympathetic tone and increased peripheral vascular resistance result in a decreased adaptability of the circulatory system to stress. ${ }^{17}$

PLMA has become popular owing to its design, wherein the flat dorsal component of the cuff of PLMA is designed to press the ventral cuff more firmly into the periglottic tissues and a wedge shaped proximal component designed to plug gaps in the proximal pharynx. A better seal coupled with a drain tube extends the rangeof surgical procedures for which this type of LMA device can be used. In addition, it also allows positive pressure ventilation in patients with high airway pressures. Therefore, it can be used in patients undergoing laparoscopic surgery. ${ }^{18}$

Elderly diabetic patients tend to have diminished physiological reserves, and alterations in autonomic function, and blunting pressor response by pharmacological means, such as opioids and anesthetic drugs is associated with adverse effects in this population. ${ }^{7,8}$

Therefore, an alteration of anesthetic technique is preferable to pharmacological means to blunt pressor response in this class of patients.

Habib et al studied the effects of remifentanil and alfentanil on the cardiovascular responses to induction of anesthesia and tracheal intubation in the elderly. They came to the conclusion that, although both remifentanil and alfentanil attenuate the pressor response to laryngoscopy and intubation, the incidence of hypotension confirms that both drugs should be used with caution in elderly patients. They also concluded that the elderly are susceptible to marked fluctuations of arterial pressure and heartrate. ${ }^{7}$
Splinter and Cervenko observed that in geriatric patients, the cardiovascular response to tracheal intubation was attenuated by fentanyl but with a marked incidence $(35 \%)$ of hypotension. ${ }^{19}$

A study by Harris et $\mathrm{al}^{8}$ also showed that elderly patients are highly sensitive to anesthetic drugs and that close titration of dosages of drugs is essential. Thus, an alteration of anesthetic technique is preferable to pharmacological means to blunt pressor response in this subset of patients.

\section{Conclusion:}

Although both endotracheal extubation and PLMA removal are associated with increased cardiovascular responses in hypertensive elderly patients, response with PLMA removal is of lesser severity and persists for a shorter period compared to endotracheal extubation.

Therefore, PLMA should be preferred in elderly hypertensivetype-2 diabetic patients for laparoscopic surgery wherever possible.

\section{Limitation}

Limitation of our study was that did not use invasive blood pressure monitoring and advanced cardiac setup and also could not do plasma catecholamine levels, which is an objective means of measuring hemodynamic stress response due to lack of facility.

\section{References:}

1. Davies,N.J.H \& Cashman, J.N 2006, Lee's Synopsis of anaesthesia, $13^{\text {th }}$ Edition Elsevier, India, P44-45.

2. Sharma B, Sahai C, Bhattacharya A, Kumar VP, Sood J. ProSeal laryngeal mask airway: A study of 100 consecutive cases of laparoscopic surgery. Indian J Anaesth 2003;47:467-72.

3. Misra MN, Ramamurthy B. The Pro-Seal LMA and the tracheal tube: A comparison of events at insertion of the airway device. Internet J Anesthesiol 2008. Vol. 16. [Last accessed on 2010 Jul 9].

4. Edwards ND, Alford AM, Dobson PMS, Peacock JE, Reilly CS. Myocardial ischaemia during tracheal intubation and extubation. Br J Anaesth 1994;73:537-9.

5. Stone JG, Foëx P, Sear JW, Johnson, Khambatta HJ, Triner L. Risk of myocardial ischemia during anaesthesia in treated and untreated hypertensive patients. BrJ Anaesth 1988;61:675-9.

6. Ghai B, Sharma A. Comparative evaluation of intraocular pressure changes subsequent to insertion of laryngeal mask airway and endotracheal tube.J Postgrad Med 2001;47:181-4.

7. Habib AS, Parker JL, Maguire AM, Rowbotham DJ, Thompson JP. Effects of Remifentanil and Alfentanil on the cardiovascular responses to induction ofanesthesia and tracheal intubation in the elderly. Br J Anaesth 2002;88:430-3. 
8. Harris T, Cook EF, Kannel W, Schatzkin A, Goldman L. Blood pressure experienceand risk of cardiovascular disease in the elderly. Hypertension 1985;7:118-24.

9. Fujii Y, Tanaka H, Toyooka H. Circulatory responses to laryngeal mask airwayinsertion or tracheal intubation in normotensive and hypertensive patients.Can J Anaesth 1995;42:32-6.

10. Brain AI, Verghese C, Strube PJ. The LMA ‘ProSeal'da laryngeal mask with anoesophageal vent. Br J Anaesth 2000;84:650-4.

11. Fujii Y, Toyoka H, Tanaka H. Cardiovascular responses to tracheal extubation or LMA removal in normotensive and hypertensive patients. Can J Anaesth1997;44:1082-6.

12. Fujii Y, Saitoh Y, Toyoka H, Tanaka H. Cardiovascular responses to trachealextubation or LMA removal in children. Can J Anaesth 1997;45:178-81.

13. Lowrie A, Johnson PL, Fell D, Robinson SL. Cardiovascular and plasma catecholamineresponses at tracheal extubation. Br J Anaesth 1992;68:261e3.
14. Hartley M, Vaughan RS. Problems associated with tracheal extubation. Br JAnaesth 1993;71:561e8.

15. Edde RR. Cardiovascular responses to extubation. Anesthesiology 1979;51:S196.

16. Wohlner EC, Usubiaga LJ, Jacoby RM, Hill GE. Cardiovascular effects of extubation.Anesthesiology 1979;51:S195.

17. Chung Frances, Evans David. Low-dose fentanyl: haemodynamic responseduring induction and intubation in geriatric patients. Can J Anesth 1985;32:622-8.

18. Sharma B, Sood J, Kumra VP. Uses of LMA in present day anesthesia. J AnesthClin Pharmacol 2007;23:5-15.

19. Splinter WM, Cervenko F. Haemodynamic responses to laryngoscopy andtracheal intubation in geriatric patients: effects of fentanyl, lidocaine and thiopentone.Can J Anaesth 1989;36:370-6. 